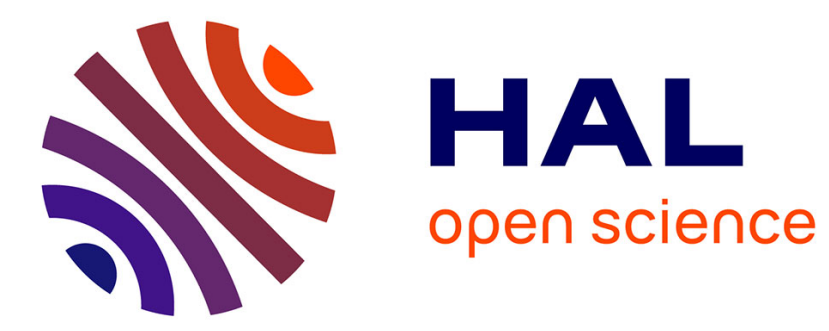

\title{
On the influence of Joule heating induced nanocrystallization on structural and magnetic properties of Co64Fe21B15 alloy
}

Shashank N. Kane, M. Coisson, Paula Tiberto, Franco Vinai, Frederic Mazaleyrat

\section{To cite this version:}

Shashank N. Kane, M. Coisson, Paula Tiberto, Franco Vinai, Frederic Mazaleyrat. On the influence of Joule heating induced nanocrystallization on structural and magnetic properties of Co64Fe21B15 alloy. Current Applied Physics, 2011, 11 (4), pp.981-985. 10.1016/j.cap.2011.01.005 . hal-00608883

\section{HAL Id: hal-00608883 https://hal.science/hal-00608883}

Submitted on 15 Jul 2011

HAL is a multi-disciplinary open access archive for the deposit and dissemination of scientific research documents, whether they are published or not. The documents may come from teaching and research institutions in France or abroad, or from public or private research centers.
L'archive ouverte pluridisciplinaire HAL, est destinée au dépôt et à la diffusion de documents scientifiques de niveau recherche, publiés ou non, émanant des établissements d'enseignement et de recherche français ou étrangers, des laboratoires publics ou privés. 
On the influence of Joule heating induced nanocrystallization on structural and magnetic properties of $\mathrm{Co}_{64} \mathrm{Fe}_{21} \mathrm{~B}_{15}$ alloy

S. N. Kane ${ }^{\mathrm{a}, 1}$, M. Coisson $^{\mathrm{b}, 2}$, P. Tiberto ${ }^{\mathrm{b}}$, F. Vinai $^{\mathrm{b}}$ and F. Mazaleyrat ${ }^{\mathrm{c}}$

${ }^{a}$ School of Physics, D. A. University, Khandwa road Campus, Indore-452001, India

${ }^{b}$ INRIM, Electromagnetism Division, Strada delle Cacce 91, 10135 Torino , Italy

${ }^{c}$ SATIE UMR 8029 CNRS, ENS de Cachan, 61, Av. du Pdt. Wilson, 94235 Cachan cedex, France

\begin{abstract}
Structural and magnetic properties of Joule heated $\mathrm{Co}_{64} \mathrm{Fe}_{21} \mathrm{~B}_{15}$ alloy has been studied. Crystallization of the specimens starts after Joule heating with 1.6 ampere current, leading to the formation of nanocrystalline $\mathrm{Co}_{80} \mathrm{Fe}_{20}$ phase with grain diameter ranging between 19 to $25 \mathrm{~nm}$. Crystallization of the specimens is found to detoriate the soft magnetic properties. Observed decrease of the hyperfine field of the amorphous component upon Joule heating suggests the increase of the boron near-neighbours to iron and the changes in the hyperfine field of the crystalline component are attributed to the changes in the environment around Fe-atom in the specimen. The coercivity is found to obey a domain wall pinning process instead of random anisotropy, as expected in soft magnetic nanocrystalline magnetic materials.
\end{abstract}

Key words : Nanocrystalline alloys, Mössbauer spectroscopy, XRD, magnetic properties.

PACS : 75.60.E , 61.18.K, 61.10.N , 75.60.E.

\footnotetext{
1 e-mail : kane_sn@yahoo.com , ${ }^{2}$ e-mail : m.coisson@inrim.it
} 


\section{Introduction}

The soft magnetic properties of amorphous ferromagnets are generally improved by low-temperature anneals, which produces relaxation of the atomic structure and a reduction of the quenched-in internal stresses [1]. Conversely, the development of a dominant crystalline fraction by performing high-temperature thermal treatments is generally seen to destroy the soft magnetic properties of amorphous alloys [2]. However, the soft magnetic properties of a certain Fe-based alloys have been improved by early Crystallization stages [3]. In the eighties, in addition to conventional furnace treatment having heating rate of the order of 0.1 to $1 \mathrm{~K} / \mathrm{s}$, a new method exploiting the heat released to the sample by an electrical current flow has been employed $[4,5]$. The current annealing techniques are characterised by rather high heating rates $\left(10^{4}\right.$ to $\left.10^{6} \mathrm{~K} / \mathrm{s}\right)$ allowing the sample to crystallize at higher temperatures with respect to furnace annealing. As a consequence, fast heating techniques [6] are currently employed in order to obtain metallic materials with attractive physical properties starting from amorphous ribbons. Among these, dc Joule heating is a convenient technique to induce structural changes [7] in a shorter time with respect to conventional furnace annealing treatments [8]. Typically, electrical current density values ranging in the interval $1 \times 10^{7}$ to $1 \times 10^{8} \mathrm{~A} / \mathrm{m}^{2}$ for time varying between 1 and $1000 \mathrm{~s}$ are exploited. This technique allows to perform annealing under a self-generated magnetic field and, consequently, to induce a magnetic anisotropy simply by using low-current densities in order to reach temperatures below the Curie temperature of the studied alloy [9]. In this technique, heating rate reaches $\sim 100 \mathrm{~K} / \mathrm{s}$, which is lower than the maximum values provided by pulse heating technique; however it remains two orders of magnitude higher with respect to conventional annealing treatment. The amorphous-to-crystalline transformation occurs several seconds after reaching a steady-state temperature, and allowing to carryout proper measurements of selected physical properties (e. g. - variation of the resistance of the specimen by passing dc current through it, providing information on crystallization of the specimen) during the structural transformation [10]. The time scale of the process is made suitable for on-line physical measurements by using an electrical current of the order of few amperes. In this case, sample heating has been monitored by measuring a structure sensitive property such as the electrical resistivity.

Both X-ray diffraction (XRD) and Mössbauer spectroscopy provide structural information on the specimen under investigation. It is of value to note that, $\mathrm{X}$-rays can not differentiate between $\mathrm{Fe}$ and Co atoms, as their scattering amplitudes are very similar. Thus, XRD essentially provides information about the average TM-TM pair correlation function (TM - Transition Metal). On the other hand, transmission Mössbauer spectroscopy measurements are sensitive to the Fe atoms only and hence they provide information about the local environment around $\mathrm{Fe}$ atoms. Furthermore, the Fe hyperfine field is more sensitive to the boron near neighbour (both number 
and the distances) as compared to the Co near-neighbours and thus hyperfine field would provide information about the variations in the metalloid near-neighbour environment.

In the present work we investigate the influence of dc Joule-heating induced nanocrystallization on structural and magnetic properties of $\mathrm{Co}_{64} \mathrm{Fe}_{21} \mathrm{~B}_{15}$ amorphous ribbons, using X-ray diffraction (XRD), Mössbauer spectroscopy and hysteresis measurements.

\section{Experimental details}

Amorphous $\mathrm{Co}_{64} \mathrm{Fe}_{21} \mathrm{~B}_{15}$ ribbons (width $\approx 6 \mathrm{~mm}$ and thickness $\approx 19 \mu \mathrm{m}$ ) were obtained by rapid solidification technique on a rotating drum. In order to carefully evaluate the electrical current value, which induces the amorphous-to-crystalline transformation, one sample has been submitted to a current ramp and the electrical resistance was continuously monitored. The electrical resistance evolution as a function of electrical current ' $I$ ' shows an increase of resistance up to $I \approx 1.9$ A and decreases for higher currents, indicating the onset of microstructural changes within the amorphous matrix (i. e. sample crystallization). Selected strips with a length of $10 \mathrm{~cm}$ have been submitted to dc Joule-heating in vacuum [7] with ' $I$ ' ranging from 0 to 2 A for 30 minutes in order to induce structural changes in the specimens. Hysteresis loops were measured using a conventional induction technique at $10 \mathrm{~Hz}$, which were used to obtain hysteresis parameters and the relative permeability. Xray diffraction $(\mathrm{XRD})$ measurements were carried out at room temperature using $\mathrm{Cu}-\mathrm{K}_{\alpha}$ radiation. $\mathrm{XRD}$ patterns were analyzed by fitting a crystalline and one amorphous component using pseudo-voigt profiles. The average grain size $D$ is obtained by Scherrer's formula using integral width of the (110) line and the lattice parameter $a$ is calculated using Nelson-Taylor-Sinclair correction in order to take into account the peak shift due to sample offset. For the amorphous phase, the first nearest neighbour distance ' $X_{m}$ ' is calculated using the expression : $X_{m}$ $=1.227 \lambda / 2 \sin \theta[11]$. Apparent area is obtained using expression -

$$
A^{*}=\frac{A_{c}}{A_{c}+A_{a}}
$$

where $A_{c}$ - area of the crystalline phase (110) peak, $A_{a}$ - area of amorphous phase main halo.

Volume of the crystallites is given by -

$$
V_{x}=\frac{1}{\frac{1-A^{*}}{A^{*}} \frac{f_{c}}{f_{a}}+1}
$$

where $f_{c}$ - scattering factor of the crystalline component and $f_{a}$ - the scattering factor of the amorphous component. These factors having dependence on the concentration of electrons, we can consider in first approximation $\mathrm{f}_{\mathrm{c}} / \mathrm{f}_{\mathrm{a}} \approx 1 /\left(1-\mathrm{C}_{\mathrm{B}}\right)$, where $\mathrm{C}_{\mathrm{B}}$ is the concentration of Boron in residual amorphous matrix. Because 
$\mathrm{C}_{\mathrm{B}}$ and $V_{x}$ are linked, it is initially considered that $V_{x}=\mathrm{A}^{*}$. The composition of the amorphous phase is then calculated and a new value of $V_{x}$ is decreased. After 3 to 4 iterations it converges to better than $1 \%$.

Volume fraction of the crystalline component is thus calculated by -

$$
V_{X R D}=\frac{A^{*}\left(1-C_{B}\right)}{1-A^{*} C_{B}}
$$

where $\mathrm{C}_{\mathrm{B}}$ is the concentration of Boron in residual amorphous matrix.

Transmission Mössbauer spectra were recorded at room temperature in constant acceleration mode using ${ }^{57} \mathrm{Co}: \mathrm{Rh}$ source and were fitted assuming a distribution of hyperfine fields using NORMOS program [12]. For Mössbauer measurements, $X$ - the $\mathrm{Co} \%$ in Fe-Co phase $\left(\mathrm{Co}_{x} \mathrm{Fe}_{1-\mathrm{x}}\right)$ is deduced as follows :

$$
\frac{1}{X}=\frac{A^{*} C_{F e}}{V_{x}}+1
$$

where $V_{x}$ is the volume fraction of crystallites obtained from XRD measurements, $A^{*}$ is the area of the crystalline phase obtained from Mössbauer measurements, $\mathrm{C}_{\mathrm{Fe}}$ is the concentration of $\mathrm{Fe}$ atoms in the parent alloy.

The apparent area is obtained using expression -

$$
A^{*}=\frac{C_{F e}{ }^{c r}}{C_{F e}{ }^{a q}}
$$

where $\mathrm{C}_{\mathrm{Fe}}{ }^{\mathrm{Cr}}$ is the concentration of $\mathrm{Fe}$ in crystalline phase and $\mathrm{C}_{\mathrm{Fe}}{ }^{\text {aq }}$ is the concentration of $\mathrm{Fe}$ in as-cast specimen.

Volume fraction of the crystalline component from Mössbauer measurements $V_{x}^{M o ̈ s s}$ is thus obtained by -

$$
V_{x}^{\text {Möss }}=\frac{\mathrm{A}^{*}}{1-\mathrm{X}}
$$

where $\mathrm{x}-\mathrm{Co} \%$ deduced from average hyperfine field 


\section{Results and discussions}

Figure 1 depicts the XRD patterns of the selected Joule heated specimens. Perusal of figure 1 shows that after annealing with a Joule heating current of 1.6 Amp. for 30 minutes, the crystallization starts and for higher Joule heating currents, crystalline fraction increases as evidenced by the presence of sharp crystalline peaks at 45.2 and $65.8^{\circ}$ (on two theta scale). Parameters obtained by analysing XRD data are depicted in table 1 . For the studied specimens, within experimental errors the $X_{m}(0.246 \pm 0.001 \mathrm{~nm})$ remains unchanged, so no definite conclusion can be drawn about the change in the mass density of the specimen from the XRD data. Table 1 also shows that the grain size of the nanocrystalline phase ranges between 19 and $25 \mathrm{~nm}$ and the corresponding volume fraction varies between 3.4 and $31.4 \%$. Volume fraction shows linear dependence with increase in the Joule heating current. Grain size of the studied samples is of the order of nanometer, although the studied samples do not contain $\mathrm{Cu}$, which is a well-known nucleating element [13]. It is worth noting that in a recent paper Ping et al. [14] have shown that in Co-rich alloy systems, Fe-Co nanocrystalline grains do not need $\mathrm{Cu}$ as a nucleating agent to precipitate nanocrystalline grains in the amorphous precursor; this result well matches with the present studies. Obtained lattice parameter ' $a$ ' values suggest that the formed nanocrystalline phase is $\mathrm{Co}_{80} \mathrm{Fe}_{20}$, and its composition almost remains almost constant with increase in Joule heating current, although volume fraction of the formed nanocrystalline phase increases, for higher Joule heating current. It should be noted that in the crystalline $\mathrm{Fe}$ and $\mathrm{Co}$, B is soluble in a very little extent only, and probably it is expelled from the developing nanocrystalline phase into the residual amorphous phase. Table 1 depicts the Joule heating current dependence of $V_{x}$ obtained by XRD measurements. For comparison, $A$ is also given (obtained from transmission Mössbauer measurements). $V_{x}$ is higher as compared with $A$, which can be attributed to the fact that: X-rays can not differentiate between Fe and Co atoms, as their scattering amplitudes are very similar. Thus, XRD essentially provides information about the average TM-TM pair correlation function, whereas Mössbauer measurements are sensitive to the Fe atoms only and hence they provide information about the local environment around Fe atoms. Additionally this difference in the area of the crystalline phase obtained from XRD and Mössbauer measurements can be attributed to the presence of an interface zone along with crystalline component and residual amorphous matrix as mentioned by Miglierini et al. [15], which has major contribution especially in the early stages of crystallization. It is worth noting that, for higher Joule heating current treatment, $\mathrm{A}^{*}$ agrees more with $\mathrm{V}_{\mathrm{XRD}}$, which can be attributed to smaller contribution from the interface.

Figure 2 shows the Mössbauer spectra and the corresponding hyperfine field distribution as obtained from the least square fit to the experimental data using NORMOS program [12]. Mössbauer spectra of the crystallized specimens consist of two components, one each corresponding the crystalline component and a residual 
amorphous matrix component. Mössbauer results also show that crystallization of the specimen starts after Joule heating with 1.6 Ampere current. Hyperfine field distribution of amorphous component is broad, while that of crystalline component is sharp. It is well known that the broad hyperfine field distribution in transition metalmetalloid metallic glasses essentially reflects the distributions of boron near-neighbours of Fe atoms, and the hyperfine field of a given iron atom decreases almost linearly with increasing number of boron near-neighbours [16].

Figure 3 shows the dependence of average hyperfine field for crystalline and amorphous phase with Joule heating current. With increase in Joule heating current, the hyperfine field for crystalline phase increases, indicating that the crystalline phase is becoming richer in Fe and the observed values of hyperfine fields for crystalline component (varying between $32 \mathrm{~T}$ to $33.5 \mathrm{~T}$ ) suggest that the hyperfine field of $32 \mathrm{~T}$ corresponds to $95 \%$ of Co in the crystalline phase and hyperfine field of $33.5 \mathrm{~T}$ corresponds to $80 \%$ of Co in the crystalline phase [17]. It should be noted that lattice parameter values show that Co content in the nanocrystals remains constant ( $80 \%$ ) with increase in Joule heating current. Obtained values of hyperfine field for the crystalline phase with highest Joule heating current can be explained assuming out-diffusion of boron from the crystalline phase, increasing the hyperfine field as observed from Mössbauer measurements. Decrease of the hyperfine field of the residual amorphous phase with increase of Joule heating current indicates the changes in the environment around $\mathrm{Fe}$ atom and supports the assumption of out-diffusion of Boron atoms from the developing nanocrystalline phase. It should be noted that Fe hyperfine field is more sensitive to the boron near neighbour as compared to the Co near-neighbours. Also, B is soluble in a very little extent in the crystalline Fe and Co, major portion of boron remains in the residual amorphous matrix, as also indicated by XRD measurements. So, as crystallization proceeds, the average number of boron near-neighbours to iron (in the amorphous phase) increases, thus reducing the iron magnetic moment, resulting in the reduction of hyperfine field corresponding to the residual amorphous phase.

Figure 4 shows the hysteresis loops of as-cast and Joule heated samples (shown with x-offset in order to be clearly visible). The measurements have been performed at a constant induction $(\mathrm{J} \approx 1.2 \mathrm{~T})$ to better evaluate the coercive field. The observed tilt in these loops for the as-cast specimen and for Joule heated specimen can be partially ascribed to the demagnetization effect occurring in them (measured specimens were $\sim 100 \mathrm{~mm}$ long, the pick up coils were $\sim 30 \mathrm{~mm}$ long and were placed on the sample region treated at a constant temperature) [7]. The tilt is seen to increase with increasing the electrical current value at which the thermal treatment has been performed clearly indicates an increase of the transverse magnetic anisotropy induced by the heating current itself. 
Variation of coercivity $H_{\mathrm{c}}$ calculated from the hysteresis loops for the as-cast and Joule heated specimens are shown in figure 5(a), whereas the variation of relative permeability is depicted in figure 5(b). Perusal of figure 5(a) shows that for Joule heating current above 1.6 Ampere, where crystallization of the specimen starts, $H_{\mathrm{c}}$ shows an appreciable increase. As crystallization proceeds, growing crystallites act as pinning centres hindering the motion of domain walls, thus increasing the coercive field. Figure 5 (b) shows that the relative permeability is almost constant as long as the annealing current does not exceed 1.5 A. Then, coherently with the coercivity data and the other results reported in the manuscript, the permeability goes down quite rapidly (this is accompanied with an increase of the crystalline fraction and increase of coercivity).

For Joule heating current above $1.6 \mathrm{~A}$, where crystallization of the specimen starts, $H_{\mathrm{c}}$ shows an appreciable increase. As crystallization proceeds, growing crystallites enhances the effective anisotropy, thus increasing the coercive field. Using the random anisotropy model proposed by Herzer [18], the average anisotropy $<\mathrm{K}>$, $<\mathrm{K}>/ \mathrm{J}_{\mathrm{s}}$ were calculated for crystalline samples (reported in table 2) using :

$$
<\mathrm{K}>=V_{x}^{2}\left(\mathrm{~K}_{1}^{4} \mathrm{D}^{6}\right) / \mathrm{A}^{3}
$$

and

$$
\mathrm{H}_{\mathrm{c}} \sim \mathrm{p}<\mathrm{K}>/ \mathrm{J}_{\mathrm{s}}
$$

where $V_{x}$ - volume fraction of crystallites, D - grain size , $\mathrm{K}_{1}-$ first anisotropy constant ( $43300 \mathrm{~J} \mathrm{~m}^{-3}$ ) [19], A exchange stiffness $\left(2.2 \times 10^{-11} \mathrm{Jm}^{-1}\right)$ calculated from virtual Curie temperature $\sim 1450 \mathrm{~K}[20]$ and $\mathrm{p}-\mathrm{a}$ dimensionless parameter.

As $H_{c}$ does not follow the Randon Anisotropy Model, a different explanation can be given for the same, as given below. Let us consider that the $\mathrm{H}_{\mathrm{c}}$ is due to domain wall pinning on Fe-Co nanoparticles due to the local demagnitising field. Using two dimensional wall bowing [21], $\mathrm{H}_{\mathrm{c}}$ is given by:

$$
H_{c}=\frac{C}{J_{s}} \frac{\rho E_{p}^{2}}{\gamma \delta_{p}^{2}}
$$

where : $\rho$ - number of particles per unit volume, $\rho=\frac{1}{(D+d)^{3}}, D-$ average grain diameter, $d$ - average distance between neighbouring nanograins., $\gamma$-wall energy $(\gamma=4 \sqrt{A K}), \delta_{\mathrm{p}}$ - interaction range between wall and defect for an elementary volume wall and defect $\delta_{p}=\delta=\sqrt{A / K}$ because $\mathrm{D}<<\sqrt{A / K}$ for an elementary volume of wall $(D+d)^{2} \delta$ the pinning energy is the product of surface fraction of particles multiplied by the demagnitizing energy of particles.

$E_{p}=\left(\frac{D}{D+d}\right)^{2} \frac{\Delta J_{s}^{2}}{6 \mu_{0}}(D+d)^{2} \delta=\frac{\Delta J_{s}^{2}}{6 \mu_{0}} D^{2} \delta=K_{d} D^{2} \delta$ 
where $-\Delta J_{s}=J_{s \text { crystal }}-J_{s}$ amorphous.

Substituting value of $\mathrm{E}_{\mathrm{p}}$ from eq. (10) in eq. (9) and writing $V_{x}=\left(\frac{D}{D+d}\right)^{3}$ yields after reduction to

$H_{c}=C \frac{K_{d}^{2}}{\gamma J_{s}} V_{x} D$

Taking $J_{s} \cong 1.5 \mathrm{~T}$ and $J_{\text {scryst. }} \cong 2 \mathrm{~T}, \mathrm{~J}_{\mathrm{s} \text { amorph. }} \cong 1.5 \mathrm{~T}\left(V_{x} \ll<\right)$ and $\gamma \sim 10^{-3}-10^{-4} \mathrm{Jm}^{-2}$; the order of magnitude is fine with $\mathrm{C} \sim 10^{-1}-10^{-2}$. Equation ( 11$)$ clearly shows that $H_{c}$ varies linearly with $V_{x} D\left(H_{c} \propto V_{x} D\right)$. Perusal of figure 6 clearly shows that $H_{c}$ varies linearly with $V_{x} D$, as is shown by equation (11).

\section{CONCLUSIONS}

X-ray diffraction, transmission Mössbauer spectroscopy and hysteresis measurements have been used to investigate the influence of Joule heating on structural and magnetic properties of $\mathrm{Co}_{64} \mathrm{Fe}_{21} \mathrm{~B}_{15}$ alloys. Joule heating leads to the formation of nanocrystalline $\mathrm{Co}_{80} \mathrm{Fe}_{20}$ phase with variation in grain size ranging between 19 $25 \mathrm{~nm}$, which can be used effectively for tailoring the soft magnetic properties. Decrease of hyperfine field for the residual amorphous phase after Joule heating suggests increase of boron near neighbours to the iron, whereas the variation of hyperfine field for the crystalline phase is attributed to the formation of $\mathrm{Co}_{80} \mathrm{Fe}_{20}$ phase and changes in the environment around Fe-atom. The coercivity was found to result from domain wall pinning by developing nanoparticles in relation with the large magnetization contrast between the two phases.

\section{ACKNOWLEDGEMENTS}

S. N. Kane acknowledges gratefully one month hospitality as invited professor from the Ecole Normale Supérieure de Cachan, Cachan (France), during November-December 2010.

\section{References}

[1] F.E. Luborsky, in “Amorphous Metallic Alloys”, Edited by F.E. Luborski (Butterworths, London 1983), p. 360.

[2] M. Baricco, F. Vinai, P. Allia, and C. Antione, Philos. Mag. B 61 (1990) 576.

[3] H. N. Ok, and A. H. Morrish, Phys. Rev. B 22 (1980) 3471.

[4] T. Jagielinski, IEEE Trans. on Magn. 19 (1983) 1225.

[5] P. Rougier, and R. Krishan, J. Phys. Paris Colloq. 46 (1985) C6-417.

[6] F. Alves, J. Magn. Magn. Mater. 226-230 (2001) 1490. 
[7] P. Allia, P. Tiberto, M. Baricco, and F. Vinai, Rev. Sci. Instr. 94 (1993) 1053.

[8] P Allia, M. Knobel, M. Baricco, P. Tiberto, and F. Vinai, J. Magn. Magn. Mater. 133 (2000) 243.

[9] M. Vàzquez, J. Gonzàlez, and A. Hernando, J. Magn. Magn. Mater. 53 (1986) 323.

[10] M. Coisson, S. N. Kane, P. Tiberto, F. Vinai, J. Magn. Magn. Mater. 271 (2004) 312; D. Muracaa, V. Cremaschia, M. Knobel, H. Sirkin, J. Magn. Magn. Mater. 320 (2008) 2068.

[11] A. Guinier, X-ray Diffraction in Crystals, Imperfect crystals and Amorphous Bodies, (Freeman, San Fransisco 1963), p. 72-143.

[12] R. A. Brand, Nucl. Inst. Meth. B 28 (1987) 398.

[13] J. D. Ayers, V. G. Harris, J. A. Sprague, W. T. Elam, and H. N. Jones, Acta Mater. 46 (1998) 1861.

[14] D. H. Ping, Y. Q. Wu, K. Hono, M. A. Willard, M. E. McHenry, and D. E. Laughlin, Scripta Mater. 45 (2001) 781 .

[15] M. Miglierini, Y. Labaye, N. Randrianantooandro, and J. M. Greneche, Mater. Sci. Eng. A 226-228 (1997) 559 .

[16] P. Panissod, J. Durand, and J. I. Budnik, Nucl. Instr. Meth. 99 (1982) 199.

[17] C.E. Johnson, M.S. Ridout, T.E. Cranshaw, and P.E. Madsen, Phys. Rev. Lett. 6 ( (1961) 450.

[18] G. Herzer, IEEE Trans. Magn. 26 (1990) 1397.

[19] R. M. Bozorth, Ferromagnetism (IEEE Press, Trenton, 1993) p 570.

[20] P. Weiss, Phys. Rev. 74 (1948) 1493.

[21] G. Bertotti, Hysteresis in Magnetism ( Academic Press Inc., San Diego 1998), p 371. 
Table 1

Parameters obtained from Mössbauer and XRD measurements. Lattice parameter $(a)$, mean grain diameter $(D)$ and volume fraction of nano-grains $\left(V_{x}\right)$ and area of the crystalline phase $(A)$ for as cast and Joule heated specimens obtained using XRD and Mössbauer measurements.

\begin{tabular}{|c|c|c|c|c|c|c|c|c|}
\hline $\begin{array}{c}\text { Joule } \\
\text { heating }\end{array}$ & \multicolumn{3}{|c|}{$\begin{array}{c}\text { From Mössbauer } \\
\text { measurements }\end{array}$} & \multicolumn{5}{|c|}{ From XRD measurements } \\
\hline $\begin{array}{l}\text { current } \\
\text { (Amp.) }\end{array}$ & $\begin{array}{c}\boldsymbol{B}_{h f} \\
(\mathbf{T}) \\
\pm 0.40\end{array}$ & $\begin{array}{c}X(\%) \\
\left(C o_{x} F e_{1-x}\right)\end{array}$ & $\begin{array}{l}A^{*} \\
(\%) \\
\pm 1\end{array}$ & $\begin{array}{c}\text { D } \\
(\mathbf{n m}) \\
\pm 2\end{array}$ & $\begin{array}{c}a \\
(\mathbf{n m}) \\
\pm 0.0001\end{array}$ & $X(\%)$ & $\begin{array}{l}A^{*} \\
(\%) \\
\left(C o_{x} F e_{1-x}\right)\end{array}$ & $\begin{array}{l}V_{X R D} \\
(\%) \\
\pm 2\end{array}$ \\
\hline 1.6 & 32.22 & 98 & 7 & 19 & 0.2836 & 79 & 4 & 3.5 \\
\hline 1.7 & 31.75 & 98 & 13 & 25 & 0.2838 & 78 & 18 & 15 \\
\hline 2.0 & 33.2 & 85 & 25 & 25 & 0.2837 & 78.5 & 37 & 31 \\
\hline
\end{tabular}

$\mathrm{A}^{*}$ - Relative area, $\mathrm{x}$ - deduced Co $\%, \mathrm{~V}_{\mathrm{XRD}}$ - crystalline volume fraction obtained from XRD measurements 
Table 2

Parameters obtained for crystallized specimens using the random anisotropy model. For comparison, values of $\mathrm{J}_{\mathrm{s}}$ and $\mathrm{H}_{\mathrm{c}}$ are also given.

\begin{tabular}{|c|c|c|c|c|}
\hline $\begin{array}{l}\text { Specimen and } \\
\text { Treatment }\end{array}$ & $\begin{array}{l}\langle K\rangle \\
\left(\mathbf{J} / \mathbf{m}^{3}\right)\end{array}$ & $\begin{array}{l}\mathbf{J}_{\mathrm{s}} \\
\text { (Tesla) }\end{array}$ & $\begin{array}{l}\langle K\rangle / J_{\mathrm{s}} \\
\left(\mathrm{J} \mathrm{m}^{-3} \text { Tesla }^{-1}\right)\end{array}$ & $\begin{array}{l}\mathbf{H}_{\mathbf{c}} \\
(\mathrm{A} / \mathrm{m})\end{array}$ \\
\hline $\begin{array}{l}\text { Joule heated } \\
1.6 \mathrm{~A} / 30 \mathrm{~min}\end{array}$ & 32 & 1.46 & 22 & 50 \\
\hline $\begin{array}{l}\text { Joule heated } \\
1.7 \mathrm{~A} / 30 \mathrm{~min}\end{array}$ & 3400 & 1.43 & 2340 & 90 \\
\hline $\begin{array}{l}\text { Joule heated } \\
2.0 \mathrm{~A} / 30 \mathrm{~min}\end{array}$ & 14000 & 1.46 & 10000 & 150 \\
\hline
\end{tabular}




\section{Figure captions}

Figure 1: $\quad$ X-ray diffractograms of selected Joule heated specimens.

Figure 2: $\quad$ Mössbauer spectra and the corresponding hyperfine field distributions for as-cast and Joule heated specimens.

Figure 3: $\quad$ Annealing current dependence of hyperfine field for amorphous and crystalline phase. Line connecting points are guide to the eye.

Figure 4: $\quad$ Hystresis loops of as-cast (A. C.) and Joule heated samples, with treatments shown with each hysteresis loop.

Figure 5: Dependence of (a) coercive field and (b) relative permeability with annealing current. Line connecting points are guide to the eye.

Figure 6 : Dependence of coercive field with $V_{x} D$ and linear fit to the points. 
Figure 1

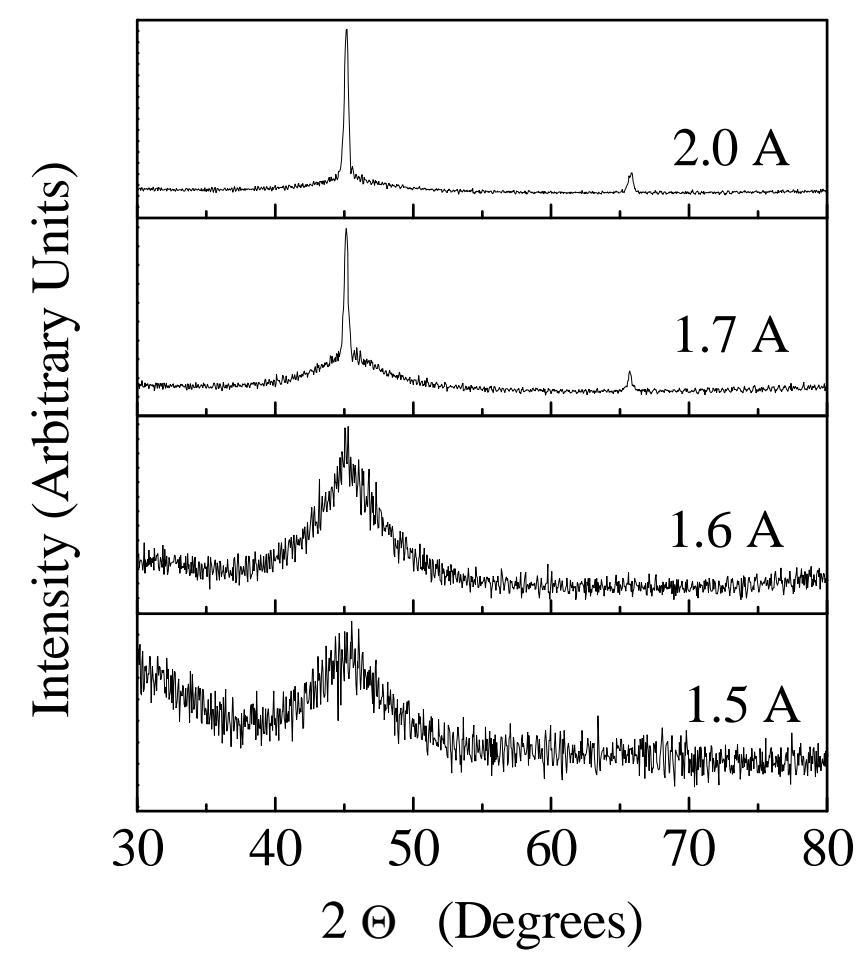


Figure 2
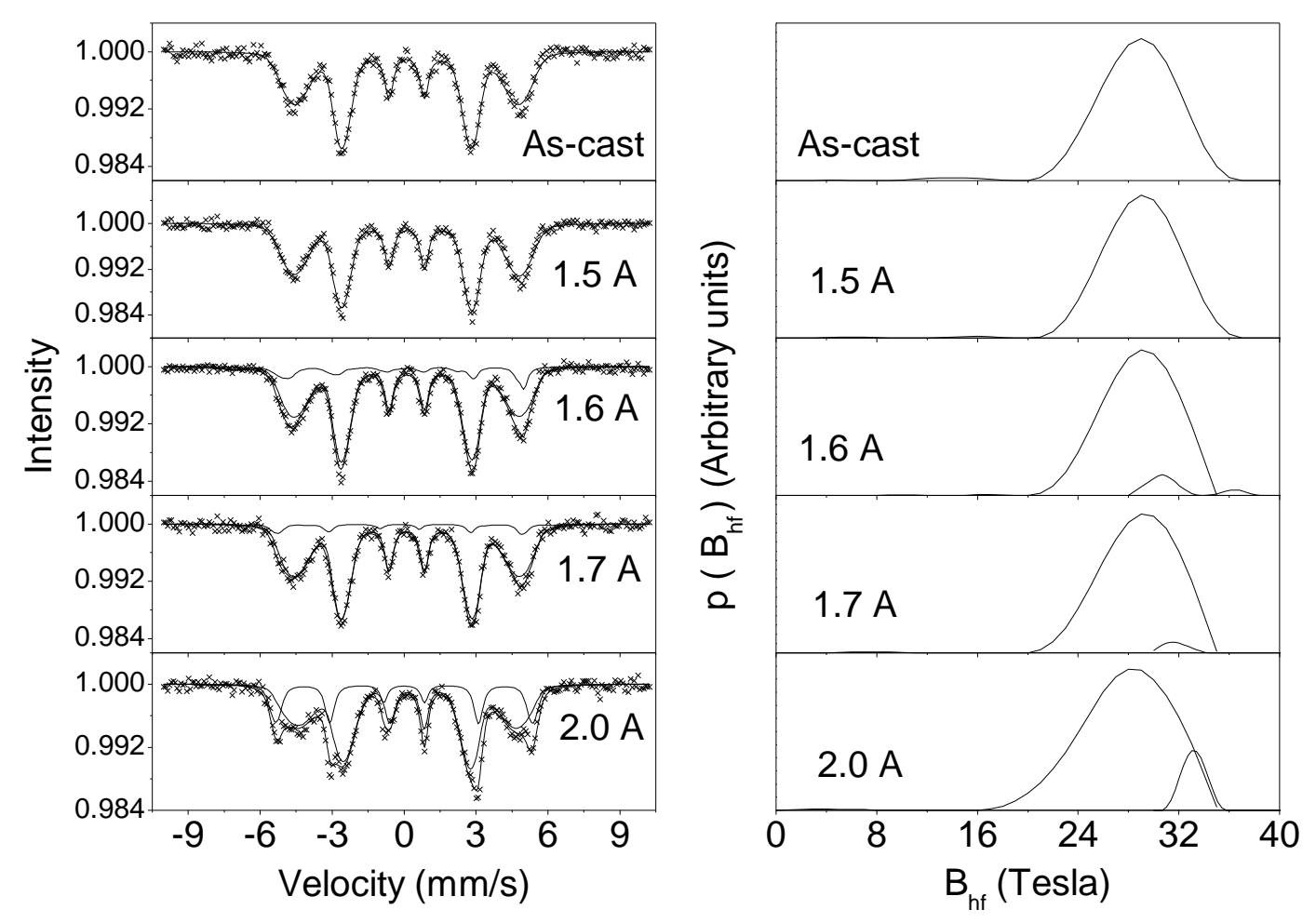
Figure 3

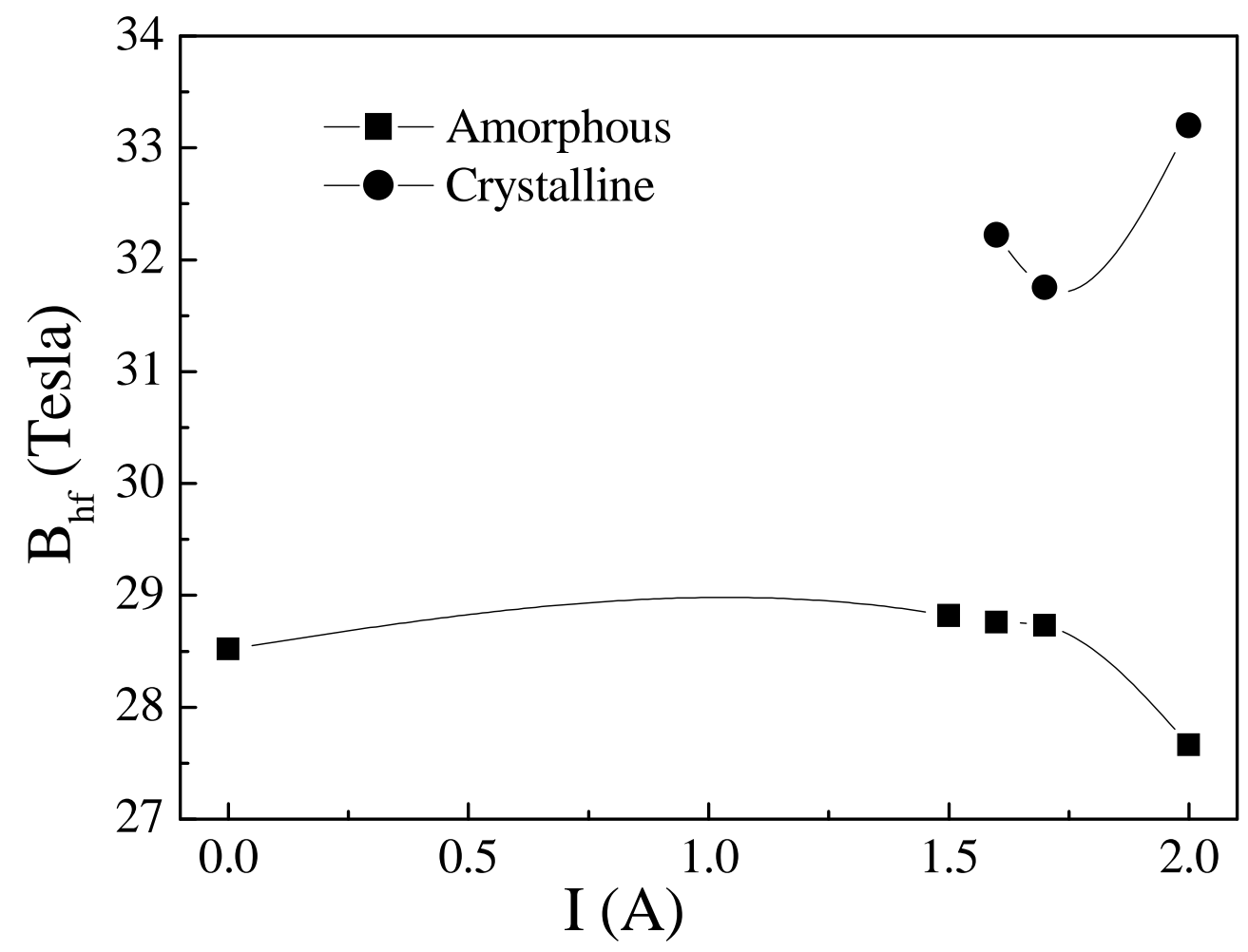


Figure 4

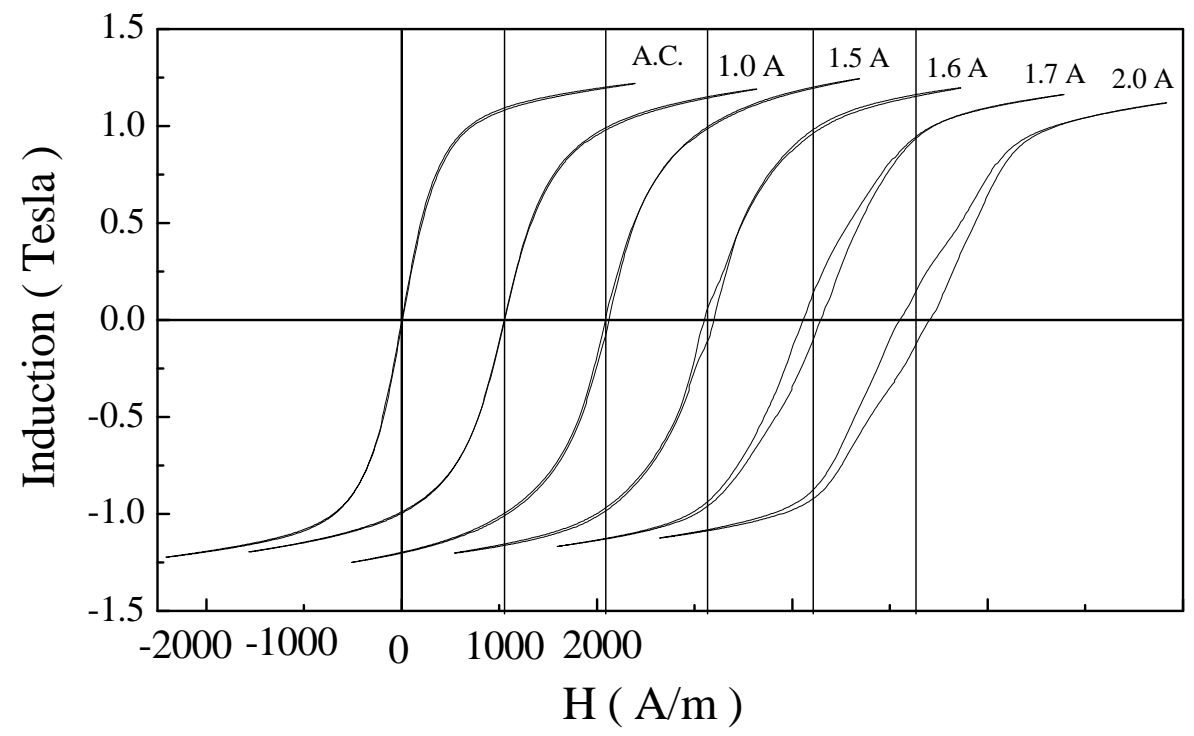


Figure 5
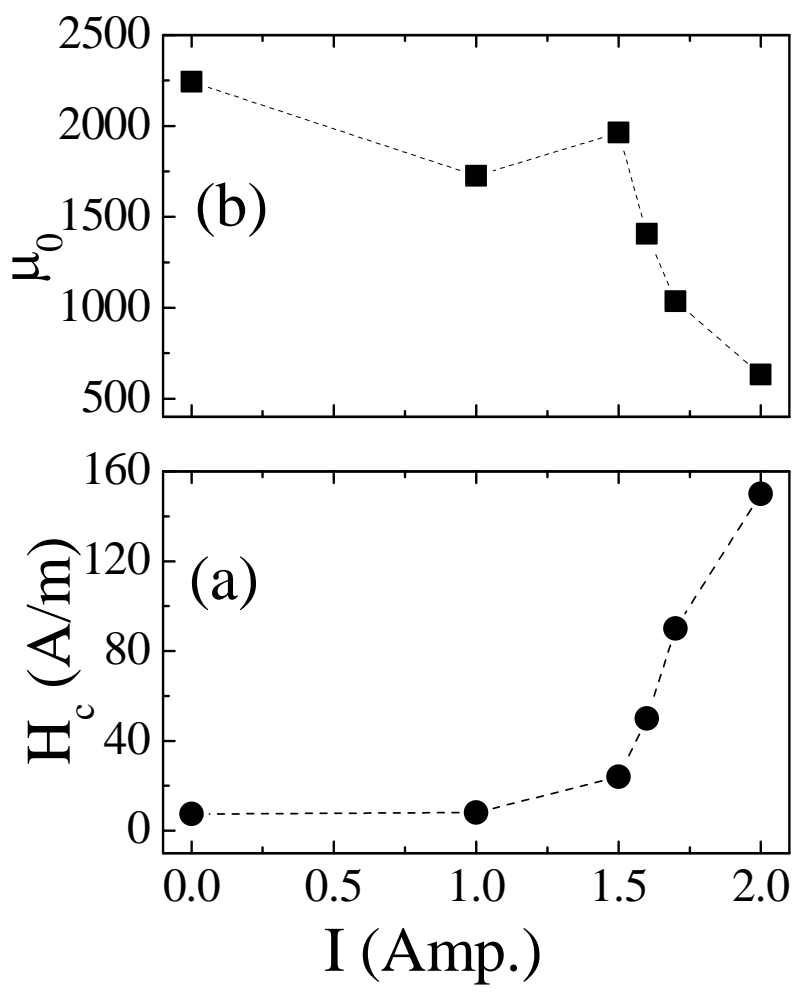
Figure 6

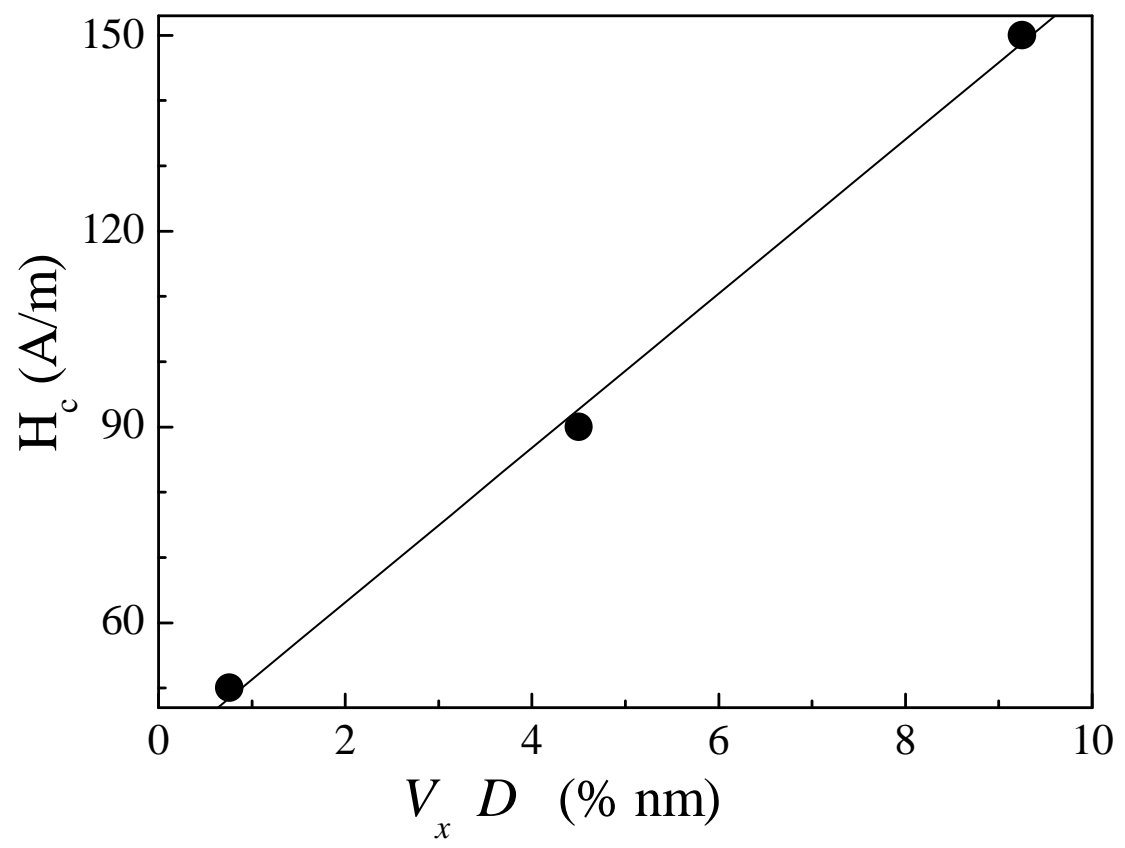

